\title{
Coronary chronic total occlusion intervention: utility or futility
}

\section{Patrick Marechal, Laurent Davin, Olivier Gach, Christophe Martinez, Mathieu Lempereur, Nicolas Lhoest \& Patrizio Lancellotti}

To cite this article: Patrick Marechal, Laurent Davin, Olivier Gach, Christophe Martinez, Mathieu Lempereur, Nicolas Lhoest \& Patrizio Lancellotti (2018): Coronary chronic total occlusion intervention: utility or futility, Expert Review of Cardiovascular Therapy, DOI: 10.1080/14779072.2018.1459187

To link to this article: https://doi.org/10.1080/14779072.2018.1459187

Accepted author version posted online: 28 Mar 2018.

Submit your article to this journal $₫$

Q View related articles $\llbracket$

View Crossmark data $₫$ 


\section{Review}

Coronary chronic total occlusion intervention: utility or futility

Patrick Marechal ${ }^{1}$, Laurent Davin ${ }^{1}$, Olivier Gach ${ }^{1}$, Christophe Martinez $^{1}$, Mathieu Lempereur $^{1}$, Nicolas Lhoest ${ }^{2}$, Patrizio Lancellotti ${ }^{1,3}$

1. University of Liège Hospital, GIGA Cardiovascular Sciences, Departments of Cardiology, Heart Valve Clinic, CHU Sart Tilman, Liège, Belgium

2. GERC, clinique de l'Orangerie, Strasbourg, France

3. Gruppo Villa Maria Care and Research, Anthea Hospital, Bari, Italy

\section{Addresses for correspondence:}

Prof. Patrizio Lancellotti

Department of Cardiology, University Hospital, Université de Liège, CHU du Sart Tilman 4000 Liège, Belgium

Tel: (32-4) 3667194

Fax: (32-4) 3667195

Email: plancellotti@chu.ulg.ac.be 


\section{Abstract}

Introduction: Despite an incidence of about $18-52 \%$ of the patients undergoing coronary angiography, chronic total occlusions (CTO) are rarely revascularised by percutaneous angioplasty (PCI). Nevertheless, current evidence suggests that successful CTO angioplasty improves symptoms, quality of life and long-term survival. During the last decade, the improvement of specific tools and techniques for these complex procedures, and the increasing experience of operators, have led to the achievement of success and complication rates almost equivalent to non-CTO angioplasty.

Areas covered: This review focuses on the clinical benefits of CTO revascularization and on appropriate patient selection.

Expert commentary: Current evidence suggests that successful CTO-PCI improves symptoms, quality of life and long-term survival. During the last years, the improvement of specific techniques for these complex procedures, and the increasing experience of operators, have led to the achievement of success and complication rates almost equivalent to non-CTO lesion angioplasty.

Key words: Total chronic coronary occlusion; angioplasty; ischemia; viability 


\section{Introduction}

Last year marked the 40th anniversary of the first coronary angioplasty performed by Andreas Gruentzig, but percutaneous treatment of chronic total occlusions (CTO) still provokes debate in the interventional cardiology community. A CTO is defined as a $100 \%$ obstructive coronary lesion present for at least 3 months, with less than, or equal to, Thrombosis in Myocardial Infarction Grade 0 flow (1) (Figure 1). Although the general prevalence is unknown, in the selected population of patients undergoing diagnostic coronary angiography, the prevalence of CTO ranges between 18 and $52 \%(2-8)$. In three Canadian centers that performed diagnostic coronary angiography on 14,439 patients, at least one CTO was present in $18.4 \%$ of patients with coronary artery disease. The prevalence was higher in patients with prior coronary artery bypass graft surgery (54\%) and lower in patients undergoing primary PCI for acute coronary syndrome with ST segment elevation (10\%). The presence of a CTO among patients with multivessel disease represents a key factor for the decision of surgical revascularization. On the other hand, for patients with isolated CTO, the option of medical treatment is often preferred. Indeed, only $10 \%$ of them are treated by percutaneous angioplasty, all this despite the presence of either invalidating symptoms or the proof of a significant myocardial ischemia (9). Historically, the weak rate of success and the high rate of complications were the main barriers to the percutaneous treatment of CTO. During the last decade, the development of specific tools and techniques dedicated to these complex procedures has allowed experienced operators to reach nearly the same success and complication rates as angioplasty of non-totally occluded vessels (nonCTO). In this article the main reasons for considering percutaneous angioplasty of CTO lesions are reviewed, taking into consideration the risk-benefit of this management strategy. 


\section{Benefits of coronary CTO revascularisation}

The main advantages of the revascularization of CTO lesions consist of the relief of angina symptoms, better quality of life and complete myocardial revascularization. Benefits in terms of survival and left ventricular function improvement, although suggested by some retrospective studies, remain however controversial in the absence of randomized and prospective data on long-term outcome versus conservative treatment (10-13).

\subsection{Symptoms of myocardial ischemia, functional capacity and quality of life}

In stable coronary artery disease the main goal of coronary revascularization depends on the symptomatic status. Overall, in patients with angina (and therefore with ischemia) the benefit of CTO treatment is for the symptoms and possibly the prognosis, while in patients with ischemia but without angina, the benefit is not symptomatic and can only be evaluated in prognostic terms. Even with well-developed collaterals, the myocardium still remains significantly ischemic, as proved by the measure of the coronary blood flow reserve by hyperemia adenosine testing (FFR - Fractional Flow Reserve) at distal bed to occlusion (14). In the randomized prospective trial, PRISON II (Primary stenting of Totally Occluded Native Coronary Arteries II), which compared drug-eluting stents to bare-metal stents in percutaneous treatment of CTOs, the proportion of patients with more than class 3 angina was reduced from 62 to $25 \%$ at 6 months after successful revascularization (15). In the FACTOR trial (Flow Cardia's Approach to Chronic Total Occlusion Recanalization), the first study demonstrating a clinical benefit of CTO revascularization, success of percutaneous revascularization was associated with a decrease of angina frequency, a significant improvement of functional capacity during exercise, and a better quality of life. This study also showed that this benefit was similar to the one observed in patients with surgical or percutaneous revascularization of non-CTO lesions (16). However, this 
improvement was only observed in previously symptomatic patients but not in asymptomatic patients. More recently, the preliminary results of the randomized EuroCTO trial, presented at the 2017 EuroPCR congress in Paris and comparing medical treatment to percutaneous revascularization in cases of $\mathrm{CTO}$, confirmed at 12 months, the improvement of the quality of life of patients treated by angioplasty, and this at a low rate of peri-procedural complications. The same applies to the DECISION-CTO trial, which showed less-frequent angina symptoms and improved physical activity (17).

\subsection{Left ventricular systolic function and end-diastolic volume}

Chronic hypoperfusion of viable myocardium due to the presence of a CTO can progressively lead to ventricular dysfunction, exercise intolerance and heart failure. The impact on the outcome of revascularization in patients with left ventricular systolic dysfunction has been recently challenged by the results of the randomized STICH trial (18). In this clinical trial, patients with multivessel disease and left ventricular systolic dysfunction improved their long-term prognosis as a result of revascularization surgery, in comparison with the medically-treated group (19). However, the STICH study did not include patients with CTO. In a recent meta-analysis (20) including 34 studies and 2,243 patients, successful percutaneous revascularization of CTO was associated with a significant increase of left ventricular function $(+4.44 \%$ ejection fraction, $\mathrm{p}<0.01)$ and a decrease of the left ventricular end-diastolic volume $\left(-6.14 \mathrm{ml} / \mathrm{m}^{2}, \mathrm{p}<0.01\right)$. In the EXPLORE trial (Percutaneous Intervention for Concurrent Chronic Total Occlusions in Patients With STEMI), comparing CTO angioplasty during the week following an acute coronary syndrome versus CTO medical treatment in patients admitted for acute myocardial infarction with ST elevation related to a coronary lesion in another territory, only disocclusion of the left anterior ascending (LAD) coronary artery was associated with an improvement of left ventricular 
systolic function (21). Beyond the importance of viable myocardium and transmural extension of myocardial necrosis, this improvement is also more related to the preservation of the integrity of the microcirculation rather than to the existence of a well-developed collateral circulation. Consequently, the existence of collaterals must not be taken into account in the decision of CTO revascularization (22).

\subsection{Complete revascularization}

The SYNTAX trial showed that incomplete revascularization is associated with greater mortality, major adverse cardiac events, and cerebrovascular events in patients treated with either percutaneous or surgical coronary revascularization (23). The adverse clinical outcomes associated with incomplete revascularization are strongly predicted by the presence of a total occlusion. Conversely, complete revascularization, achieved either by angioplasty or by surgery, has clearly shown a long-term benefit on cardiovascular mortality $(-30 \%)$ and on the occurrence of myocardial infarction (-22\%) (24). Historically, before the development of equipment and techniques dedicated to CTO's percutaneous treatment, this goal was more likely to be achieved through surgery than with angioplasty (63 versus 57\%) (25). However, surgery results remain controversial. For instance, the PRAGUE-4 trial (Primary Angioplasty in patients transferred from General community hospitals to specialized PTCA Units with or without Emergency Thrombolysis) compared off-pump versus on-pump coronary artery bypass grafting on long-term graft patency; although all bypass grafts placed distal to a collateralized LAD CTO remained patent at 1-year, only $23 \%$ of those grafts remained patent when placed on the left circumflex or right coronary artery (26). Moreover, in the SYNTAX trial (SYNergy between PCI with TAXus and Cardiac Surgery), comparing angioplasty/drug-eluting stenting to surgery in a population of patients with multivessel or left main disease, $32 \%$ of the totally occluded vessels finally never 
received a graft, leading to a high rate of incomplete revascularization (27). Therefore, many CTOs do not receive a graft when referred to surgery and when a graft is placed there is evidence that long-term patency is weak.

\subsection{Myocardial electrical stability}

The incidence of sudden cardiac death in patients with non-revascularized CTO is five times higher (2.7 vs. $0.5 \%)$ than in those with successfully treated CTO (28). Currently, there is little data in favor of the improvement of electrical stability after the percutaneous treatment of CTOs. In one of these retrospective studies, Nombela-Franco et al. showed in 162 patients requiring an implantable cardioverter-defibrillator for a left ventricular dysfunction related to ischemic cardiomyopathy, that the presence of a CTO was significantly associated with ventricular arrhythmias $(\mathrm{p}=0.003)(29)$. Two arrhythmogenic factors could be responsible for ventricular tachycardia: 1) the ischemia induced by insufficient myocardial perfusion facilitating the onset of abnormal electrical automaticity of myocardial cells; 2) the presence of viable cells within fibrous tissue due to myocardial infarction generating re-entry circuits. Restoring normal perfusion in ischemic zones could, therefore, improve the electrical stability of patients with ischemic left ventricular dysfunction.

However, a subsequent study failed to confirm these findings and found that the presence of a CTO in patients with ischemic cardiomyopathy was not associated with higher mortality or incidence of ventricular arrhythmias, and revascularization of CTOs was not associated with improved outcomes (30).

\subsection{Survival}

The presence of a CTO is associated with an unfavourable clinical prognosis, linked with a significant increase of mortality compared to patients without CTO (7). In patients 
undergoing primary PCI for acute myocardial infarction the presence of a CTO in a noninfarct related artery is associated with an increased size of the infarction area and a decrease in left ventricular function. It also represents an independent predictor of increased risk of mortality at short and long-term (31-33), partly related to hemodynamic instability and a greater rate of cardiogenic shock. A recent meta-analysis, including 27 trials and 15,432 patients, confirmed a significant decrease of $48 \%$ of long-term mortality in patients with a successful CTO revascularization (20). Nevertheless, these results are limited in their application by the fact that this study was an observational study which compared successful versus failed CTO procedures, and therefore could only suggest that survival depends on procedural success. A large United Kingdom Database, including 13,443 patients, has recently shown that successful CTO revascularization leads to significant mortality reduction (about 28\%), and this independent of the coronary vessel treated. This has also been shown in two observational, non-randomized and retrospective studies which compared aggressive revascularization, either by $\mathrm{CABG}$ or by angioplasty, and medical therapy in patients with CTO and well-developed collateral circulation, with a significant reduction of long-term risk of cardiac death, all-cause death and MACE.(34-35) However, another database including 1,734 patients has suggested that this survival benefit is only observed when LAD or left circumflex arteries are the target vessels (36-37).

\section{Patient selection and indications for CTO revascularization}

Although CTOs are prevalent in patients with known coronary artery disease, the rate of attempted interventions on these lesions varies greatly depending on geographic location and regional practice patterns. Current guidelines recommend coronary artery bypass surgery to improve survival in patients with significant triple-vessel coronary artery disease or doublevessel disease involving the proximal left anterior descending artery (38). It is recommended 
that patients with diabetes and multi-vessel coronary artery disease undergo surgical revascularization in preference to percutaneous angioplasty, particularly if a left internal mammary artery graft can be anastomosed to the left anterior descending artery. Revascularization of significant coronary lesions by either modality is reasonable in order to improve symptoms in patients with refractory angina despite medical therapy (39). According to the current guidelines, CTO revascularization has to be considered in patients with angina and/or in those for whom a significant improvement of the ischemia in the territory depending on the occluded vessel is expected (class IIa, level of evidence B) (38). In practice (Figure 2) (39), CTO revascularization: 1) requires an individualized risk-benefit analysis encompassing clinical symptoms, level of medical therapy, age and comorbid disease, angiographic (J-CTO score and PROGRESS-CTO score) and technical considerations; 2) must be performed by operators with appropriate expertise; 3) are considered in cases of: a) refractory angina despite optimal medical treatment, b) in the presence of moderate to severe ischemic burden ( $\geq 10 \%$ ischemic myocardium), $c$ ) in the presence of a documented viability in the myocardial territory depending on the CTO vessel.

\section{Results and complications of percutaneous CTO revascularization}

The success rates of CTO procedures are significantly lower than for non-CTO lesions (59 vs. 96\%) (Table 1). However, these results vary greatly depending on the operating volume of the center and the operator's experience, achieving more than $85 \%$ for the most experienced operators (40-44). The same applies to the rates of complications approaching those of non-CTO lesions, when these procedures are carried out by experts (Figure 3) (4546). For instance, the risk of coronary perforation from the antegrade and retrograde approach was limited to $0.4 \%$ in the Japanese CTO registry (47). Overall, major complications (death $0.22 \%$, tamponade $0.6 \%$ ) were reported in $1.8 \%$. It is considered that 
an operator must have completed 300 CTOs to be familiar with these complex procedures and maintain a volume of 50 procedures per year to keep the expertise acquired; all this in centers reaching a minimum volume of 1,000 angioplasties of non-CTO lesions per year (48). The use of drug-eluting stents yields permeability rates at 6-9 months in the order of $96 \%$, comparable to the 1-year permeability of the arterial mammary grafts and higher than those of venous grafts $(80 \%)$ used in the event of surgical revascularization (49-50). These procedures are nonetheless associated with a significant increase in radiation exposure associated with longer procedural times (risk of radiation skin injury, maybe increased risk for cancer) and greater use of contrast product (risk of precipitating renal failure) and therefore, contra-indicated in severe kidney function impairment. However, these disadvantages can be alleviated by the improvement of the current imaging techniques.

\section{Technical considerations}

The goal of percutaneous CTO revascularization is to achieve the safest and most efficient procedure outcome. Procedural success depends on thorough planning with careful review of the angiogram including stump morphology, length of occlusion, in-CTO tortuosity $\left(>45^{\circ}\right)$, calcification, degree of disease in the "distal landing zone" and presence and extent of "interventional collaterals". In selected cases, CT coronary angiography may assist in preplanning by providing additional morphological features of the CTO; in particular vessel course, tortuosity and calcification (51). CTO lesions are graded as easy, intermediate, difficult, and very difficult (JCTO scores of $0,1,2$, and $\geq 3$, respectively). The choice between antegrade and retrograde approaches using wire escalation or dissection re-entry methods depends on the CTO anatomy and operator's experience (52). The hybrid algorithm (antegrade versus retrograde and true lumen strategy versus dissection re-entry) should be employed if failing to progress smoothly (53). Antegrade wire escalation (AWE) is the 
suggested first strategy for CTO characterized by a clear proximal cap, a good distal landing zone, and a short lesion length $(<20 \mathrm{~mm})$. For longer lesions, antegrade dissection re-entry is preferred. In CTOs with proximal cap ambiguity, or a diseased distal landing zone, but with 'good' interventional collaterals, a retrograde approach is recommended. Retrograde wire escalation (RWE) is preferred for short lesions, and retrograde dissection re-entry (RDR) for longer lesions (41). The J-CTO score is often used to define the degree of CTO complexity (Multicenter Chronic Total Occlusion Registry in Japan). This score uses five variables (occlusion length $>20 \mathrm{~mm}$, blunt stump, CTO calcification, CTO tortuosity, and prior failed attempt) to create a score that predicts successful guidewire crossing within the first $30 \mathrm{~min}$ (47). Although its predictive capability with regard to procedural success is inconsistent, it is correlated with the duration required for successful intimal wire crossing. Traditional factors that predict a lower procedural success rate include length of occlusion $>$ $20 \mathrm{~mm}$, presence of calcification within the lesion and/or artery, native vessel CTO after coronary artery bypass surgery and the presence of bridging collaterals $(47,54,55)$. Another score, the Progress-CTO score, could also be used to predict the technical success of CTO percutaneous coronary intervention. This score takes into account the proximal cap ambiguity, the absence of 'interventional' collaterals (for the retrograde approach), moderate or severe tortuosity and circumflex CTO. The success prediction of the procedure depends on the score obtained: $0: 98.2 \%, 1: 97.5 \%, 2: 91.6 \%, \geq 3: 76.7 \%(56)$. Procedural outcome is also linked to: 1) a dual interventional cardiologist approach, 2) dedicated laboratory time to prevent time constraints, 3) pre-procedure laboratory inventory review to ensure necessary equipment is available, 4) contralateral injection. The decision about when to stop the procedure relies heavily on the operator's judgement and must be individualized $(53,57)$. The occurrence of a complication is in most cases an indication to stop the procedure. 


\section{Conclusion}

CTO, which is associated with decreased quality of life and worse outcomes, is commonly found during coronary angiography. Successful percutaneous coronary intervention of CTO is likely to be associated with an improvement in patient's symptoms, quality of life, left ventricular function, and survival. However, a failed procedure is also likely to be associated with a higher risk of complications and adverse short-term outcomes. Outcomes after CTO angioplasty depend on proper patient selection (resistant angina, large areas of ischemia, and anatomic suitability for antegrade, retrograde, and/or subintimal recanalization) and on the operator's personal experience.

\section{Expert commentary}

Current evidence suggests that successful CTO-PCI improves symptoms, quality of life, left ventricular function, prognosis and long-term survival of patients in the chronic and stable phase of coronary artery disease. During the last years, the improvement of specific techniques for these complex procedures (The Hybrid Algorithm), improvements in CTOdedicated equipment, and the increasing experience of operators have led to success and complications rates almost equivalent to non-CTO lesion angioplasty.

Nevertheless, the two prospective studies, EURO-CTO and DECISION-CTO, failed to definitively confirm the usefulness of CTO angioplasty, mainly due to slow recruitment rates. Nevertheless, the overall mortality in DECISION-CTO was slightly lower in the PCI arm than in the OMT arm (3.0\% vs. 4.4\% at 3-year follow-up, and 7.9\% at 5-year follow-up) with a reduction of $50 \%$ in the specific cases of cardiac death at the third year $(1.9 \% \mathrm{vs}$. 3.6\%). Moreover, the obtained results indicate an improved Quality of Life in patients undergoing CTO angioplasty, coupled with a low rate of periprocedural complications $(1.5 \%$ pericardial tamponade and no death), may inform the clinical decision-making process when considering CTO angioplasty. Due to high costs and no risk-free procedures, there is an 
urgent need for more prospective randomized studies to support this therapy. In pending randomized studies, patients should be selected very carefully, especially if they are asymptomatic or with very few symptoms, and the benefits obtained in terms of complications during the procedure, the quality of life obtained and further ischemic events avoided should be evaluated systematically.

\section{Five-year view}

Recent years have seen the development of specialist operators, techniques and equipment that have improved success rates in CTO angioplasty. However, whether to revascularize, and by which modality, is still a matter of discussion. In the near future efforts should be made to more accurately define the risks of complications and failed interventions versus the benefits of improved long-term outcome after successful CTO revascularization.

\section{Key issues}

- The prevalence of CTO in patients undergoing coronary angiography varies, ranging between $18 \%$ and $52 \%$ depending on the clinical profile of the patient being examined.

- Patients with a CTO often have stable exertional angina and may develop progressive left ventricular dysfunction.

- Long-term medical therapy is frequently regarded as an adequate management strategy of CTO with surgical intervention for refractory angina.

- Treatment of CTO has recently gained interest as a result of technical angioplasty improvements that enable higher revascularization success rates than a few years ago.

- Successful percutaneous coronary intervention for CTO is associated with improvement in patient symptoms, quality of life, left ventricular function, and survival, compared with those with unsuccessful CTO angioplasty.

- The current evidence supporting CTO angioplasty mostly comes from observational studies, and no randomized study comparing percutaneous treatment with medical treatment has yet been published. 
- Given the inherent complexity and technical challenges of CTO angioplasty, patients who may benefit from these interventions should be referred to high volume centres with experienced operators.

- Education and training which can help the operator to achieve a good procedural outcome for the patient are both encouraged. 


\section{Funding}

This paper was not funded.

\section{Declaration of interest}

The authors have no relevant affiliations or financial involvement with any organization or entity with a financial interest in or financial conflict with the subject matter or materials discussed in the manuscript. This includes employment, consultancies, honoraria, stock ownership or options, expert testimony, grants or patents received or pending, or royalties. Peer reviewers on this manuscript have no relevant financial or other relationships to disclose. 


\section{References}

Papers of special note have been highlighted as:

* of interest

** of considerable interest

1. Sianos G, Werner GS, Galas AR, et al. Recanalisation of chronic total coronary occlusions: 2012 consensus document from the EuroCTO club. Eurointervention 2012; 8:139-145.

2. Grantham JA, Marso SP, Spertus JH et al. Chronic Total Occlusion Angioplasty in the United States. JACC Cardiovasc Interv 2009;6:479-486

3. Khan JK. Angiographic suitability for catheter revascularization of total coronary occlusions in patients from a community hospital setting. Am Heart J. 1993; 126: 561-4.

4. Christofferson RD, Lehmann KG, Martin GV, et al. Effect of chronic total coronary occlusion on treatment strategy. Am J Cardiol. 2005; 95: 1088-91.

5. Srininas VS, Brooks MM, Detre KM, et al. Contemporary percutaneous coronary intervention versus balloon angioplasty for multivessel coronary artery disease: a comparison of the National, Lung and Blood Institute Dynamic Registry and the Bypass Angioplasty Revascularization Investigation (BARI) study. Circulation. 2002; 106: 1627-33.

6. Yamamoto E, Natsuaki M, Morimoto T, et al. Long-term outcomes after percutaneous coronary intervention for chronic total occlusion (from the CREDO-Kyoto registry cohort-2). Am J Cardiol. 2013; 112: 767-74.

7. Fefer P, Knudtson ML, Cheema AN, et al. Current perspectives on coronary chronic total occlusions: the Canadian Multicenter Chronic Total Occlusion Registry. J Am Coll Cardiol. 2012; 59:991-7. 
8. Jeroudi OM, Alomar ME, Michael TT, et al. Prevalence and management of coronary chronic total occlusions in a tertiary veterans affairs hospital. Catheter Cardiovasc. Interv. 2014; 84(4): 637-43.

9. Ramunddal T, Hoebers L, Henriques JP et al. Chronic Total Occlusions in Sweden - a report from the Swedish Coronary Angiography and Angioplasty Registry. PLoS One 2014; 9; e103850.

10. Joyal D, Mansour D. How to justify CTO Revascularisation in Rinfret $S$ Ed. Percutaneous Intervention for Coronary Chronic Total Occlusion, The Hybrid Approach, Sprynger Quebec 2016:1-11.

11. Joyal D, Afilalo J, Rinfret S. Effectiveness of recanalization of chronic total occlusions: a systematic review and meta-analysis. Am Heart J. 2010,160:179-187.

12. Khan MF, Wendel CS, Thai HM et al. Effects of percutaneous revascularization of chronic total occlusions on clinical outcomes: a meta-analysis comparing successful versus failed percutaneous intervention for chronic total occlusions. Catheter Cardiovasc. Interv. 2013,82: 95-107. . * This paper provides a very interesting metaanalysis concerning the outcomes of the patients successfully treated by PCI recanalization of a CTO and underlines the benefits of this intervention with lower rates of MACE and reduced needs for subsequent bypass surgery. The difference in long-term mortality remained significant.

13. Li R, Yang S, Tang L et al. - Meta-analysis of the effects of percutaneous coronary intervention on chronic total occlusions. J Cardiothorac Surgery 2014; 9-41.

14. Werner GS, Surber R, Ferrari M et al. The functional reserve of collaterals supplying long-term chronic total coronary occlusions in patients without prior myocardial infarction. Eur Heart J 2006; 27:2406-2412. 
15. Suttorp MJ, Laarman GJ, Rachel BM et al. Primary stenting of Totally Occluded Native Coronary Arteries II (PRISON II): a randomized comparison of bare metal stent implantation with sirolimus-eluting stent implantation for the treatment of total coronary occlusions. Circulation 2006:114; 921-928. ** This randomized study suggests that opening of total coronary occlusions can be of benefit by restoring blood flow to a hibernating myocardium ant thus improving symptoms and left ventricular function.

16. Grantham JA, Jones PG, Cannon L et al. Quantifying the early health status benefits of successful chronic total occlusion recanalization: results from the Flow Cardia's Approach to Chronic Total Occlusion Recanalization (FACTOR) Trial. Circ Cardiovasc Qual Outcomes 2010; 3:284-290. ** In this publication, the data highlight that the successful CTO recanalization provides more benefits in symptomatic patients, with improvements of symptoms, function and quality of life.

17. Gutiérrez-Chico JL, Louvard Y. DECISION-CTO: A "negative" clinical trial? Really? Cardiol. Journal 2017. Vol 24, No. 3:231-233.

18. Velazquez EJ, Lee KL, Deja MA, et al. Coronary-artery bypass surgery in patients with left ventricular dysfunction. N Engl J Med 2011; 364: 1607-1616.

19. Velazquez EJ, Lee KL, Jones RH, et al. Coronary-artery bypass surgery in patients with ischemic Cardiomyopathy. N Engl J Med 2016; 374(16): 1511-20.

20. Hoebers LP, Claessen BE, Elias J et al. Meta-analysis on the impact of percutaneous coronary intervention of chronic total occlusions on left ventricular function and clinical outcome. Int J Cardiol 2015; 187:90-96.

21. Henriques JP, Hoebers LP, Ramunddal T et al. Percutaneous Intervention for Concurrent Chronic Total Occlusions in Patients With STEMI: The EXPLORE Trial. J Am Coll Cardiol 2016; 68:1622-1632. ** This trial confirms that there is no clear benefit for additional CTO PCI within the week after primary PCI for STEMI, but suggests that 
patients in particular with CTO located in the left anterior descending coronary artery had a significant higher LVEF after CTO recanalization.

22. Werner GS, Surber R, Kuethe F et al. Collaterals and the recovery on left ventricular function after recanalization of a chronic total coronary occlusion. Am Heart J, 2005; 149:129-137.

23. Mohr FW, Morice MC, Kappetein AP, Feldman TE, Stahle E, Colombo A, et al. Coronary artery bypass surgery versus percutaneous coronary intervention in patients with three vessel disease and left main coronary disease: 5 year follow up of the randomised, clinical SYNTAX trial. Lancet 2013; 381:629-638.

24. Garcia S, Sandoval Y, Roukoz H et al. Outcomes after complete versus incomplete revascularization in patients with multivessel coronary artery disease: a meta-analysis of 89,883 patients enrolled in randomized clinical trials and observational studies. $J \mathrm{Am}$ Coll Cardiol 2013; 62:1421-1431. * This review and meta-analysis of a large group of patients included in 35 studies showed that a complete revascularization may be the optimal goal among patients with multivessel coronary artery disease.

25. Head SJ, Mack MJ, Holmes Jr et al. Incidence, predictors and outcomes of incomplete revascularization after percutaneous coronary intervention and coronary artery bypass grafting: a subgroup analysis of 3-year SYNTAX data. Eur J Cardiothorac Surg 2012; 41:535-541.

26. Widimsky P, Straka Z, Stros $\mathrm{P}$ et al. One-year coronary bypass graft potency: a randomized comparison between off-pump and on-pump surgery angiographic results of the Prague- 4 trial. Circulation 2004;110:3418-3423.

27. Serruys PW, Morice MC, Kappetein AP et al. Percutaneous coronary intervention versus coronary artery bypass grafting for severe coronary artery disease. $N$ Engl $J$ Med 2009;360:961-972. 
28. Godino C, Bassanelli G, Economou FI et al. Predictors of cardiac death in patients with coronary chronic total occlusion not revascularized by PCI. Int J Cardiol 2013; 168:1402-1409. * This double-center study established that CTO patients without revascularization had higher rate of cardiac mortality and sudden cardiac death. The most independent predictors of cardiac death were chronic renal failure, low-LVEF and insulin-dependent diabetes mellitus.

29. Nombela-Franco L, Mitroi CD, Fernandez-Lozano I et al. Ventricular arrhythmias among implantable cardioverter-defibrillator recipients for primary prevention: impact of chronic total coronary occlusion (VACTO Primary Study). Circ Arrhythm Electrophysiol $2012 ; 1: 147-154$.

30. Raja V, Wiegn $\mathrm{P}$, Obel $\mathrm{O}$, et al. Impact of Chronic total occlusions and coronary revascularization on all-cause mortality and the incidence of ventricular arrhythmias in patients with ischemic cardiomyopathy. Am J Cardiol. 2015 Nov 1; 116(9): 1358-62.

31. Hoebers LP, Claessen BE, Dangas GD et al. Contemporary overview and clinical perspectives of chronic total occlusions. Nat Rev Cardiol 2014; 11:458-469.

32. Claessen BE, Dangas GD, Weisz G et al. Prognostic impact of a chronic total occlusion in a non-infarct related artery in patients with ST-segment elevation myocardial infarction: 3-year results from the HORIZON-AMI trial. Eur Heart J 2012; 33:768-775.

33. Hoebers LP, Vis MM, Claessen BE et al. The impact of multivessel disease with and without a co-existing chronic total coronary occlusion on short- and long-term mortality in ST-elevation myocardial infarction patients with and without cardiogenic shock. Eur $J$ Heart Fail 2013; 15:425-432.

34. Woo JJ, Jeong HY, Seung-Hyuk C, et al. Long-Term Survival Benefit of Revascularization Compared With Medical Therapy in Patients With Coronary Chronic 
Total Occlusion and Well-Developed Collateral Circulation. JACC Cardiovasc Interv 2015; 8(2): 271-79.

35. Se Yeon C, Byoung Geol C, Seung-Woon R, et al: Percutaneous Intervention Versus Optimal Medical Therapy for Chronic Total Coronary Occlusion With Well-Developed Collaterals. J Am Heart Assoc. 2017; 6:e006357.

36. George S, Cockburn J, Clayton TC et al. Long-term follow-up of elective chronic total coronary occlusion angioplasty: Analysis from the U.K. Central Cardiac Audit Database. J Am Coll Cardiol 2014;64:235-243.

37. Claessen BE, Dangas GD, Godino C et al. - Impact of target vessel on long-term survival after percutaneous coronary intervention for chronic total occlusions. Catheter Cardiovasc Inter 2013;82:76-82.

38. Windecker S, Kohl P, Alfonso F et al. 2014 ESC/EACTS Guidelines on myocardial revascularization: The task force on myocardial revascularization of the European Society of Cardiology (ESC) and the European Association for Cardio-Thoracic Surgery (EACTS). Developed with the special contribution of the European Association of Percutaneous Cardiovascular Intervention (EAPCI). Eur Heart J 2014; 3: 2541-2619.

39. Galassi RG, Brilakis ES, Bouchais $M$ et al. Appropriateness of percutaneous revascularization of coronary chronic total occlusions: an overview. Eur Heart $J$ 2016; 37: $2692-2700$.

40. Christopoulos G, Karmpaliotis D, Alaswad K, et al. Application and outcomes of a hybrid approach to chronic total occlusion percutaneous intervention in a contemporary multicentre US registry. Int J Cardiol 2015; 198: 222-8.

41. Maeremans J, Walsh S, Knaapen P, et al. The hybrid Algorithm for treating chronic total occlusions in Europe: the recharge registry. J Am Coll Cardiol 2016; 68: 1958-70. * This 
international registry confirmed that the hybrid algorithm should be used to improve procedural outcomes with high procedure success rates and low event rate.

42. Galassi AR, Boukhris M, Azzarelli S, et al. Percutaneous coronary revascularization for chronic total occlusions: a novel predictive score of technical failure using advanced technologies. JACC Cardiovasc Interv 2016; 9: 911-22. * This first report of the ERCTO registry by the EuroCTO club showed a high procedural success rate obtained in a "real-world" consecutive series of patients, comparable with those reported by Japanese registries.

43. Wilson WM, Walsh SJ, Yan AT, et al. Hybrid approach improves success of chronic total occlusion angioplasty. Heart 2016; 102: 1486-93.

44. Habara M, Tsuchikane E, Muramatsu T, et al. Comparison of percutaneous coronary intervention for chronic total occlusion outcome according to operator experience from the Japanese retrograde summit registry. Catheter Cardiovasc Interv 2016; 87: 1027-35.

45. Brilakis ES, Banerjee S, Karmpaliotis D et al. Procedural outcomes of chronic total occlusion percutaneous coronary intervention: a report from the NCDR (National Cardiovascular Data Registry). JACC Cardiovasc Interv 2015; 8:245-253.

46. Galassi AR, Tomasello SD, Reifart $\mathrm{N}$ et al. In hospital outcomes of percutaneous coronary intervention in patients with chronic total occlusion: Insights from the ERCTO (European Registry of Chronic Total Occlusion) registry. Eurointervention 2011;7:472479.

47. Morino Y, Abe M, Morimoto T, et al. Predicting successful guidewire crossing through chronic total occlusion of native coronary lesions within 30 minutes: the J-CTO (Multicenter CTO Registry in Japan) score as a difficulty grading and time assessment tool. JACC Cardiovasc Interv 2011;4:213-21. 
48. Di Mario C, Werner GS, Sianos G et al. European perspective in the recanalization of Chronic Total Occlusions (CTO): consensus document from the EuroCTO Club. Eurointervention 2007;3:30-33.

49. Valenti R, Vergara R, Migliorini A et al. Predictors of reocclusion after successful drugeluting stent-supported percutaneous coronary intervention of chronic total occlusion. $J$ Am Coll Cardiol 2013;61:545-550.

50. Goldman S, Zadina K, Moritz T et al. Long-term patency of saphenous vein and left internal mammary artery grafts after coronary artery bypass surgery : Results from a Department of Veterans Affairs Cooperative Study. J Am Coll Cardiol 2004;44:21492156.

51. Soon KH, Selvanayagam JB, Cox N, Kelly AM, Bell KW, LimYL. Percutaneous revascularization of chronic total occlusions: review of the role of invasive and noninvasive imaging modalities. Int J Cardiol 2007;116:1-6.

52. Maiello L, Colombo A, Gianrossi R, MutinelliMR, Bouzon R, Thomas J, et al. Coronary angioplasty of chronic occlusions: factors predictive of procedural success. Am Heart J $1992 ; 124: 581-4$

53. Brilakis ES, Grantham JA, Rinfret S,Wyman RM, Burke MN, Karmpaliotis D, et al. A percutaneous treatment algorithm for crossing coronary chronic total occlusions. JACC Cardiovasc Interv 2012;5:367-79.

54. Noguchi T,Miyazaki S,Morii I, Daikoku S, Goto Y, Nonogi H. Percutaneous transluminal coronary angioplasty of chronic total occlusions. Determinants of primary success and long-term clinical outcome. Catheter Cardiovasc Interv 2000;49:258-64.

55. Azzalini L, Ojeda S, Karatasakis A, et al. Long-Term Outcomes of Percutaneous Coronary Intervention for Chronic Total Occlusion in Patients Who Have Undergone Coronary Artery Bypass Grafting vs Those Who Have Not. Can J Cardiol. 2018;34:310- 
318.

56. Christopoulos G, Kandzari DE, Yeh RW, et al. Development and Validation of a Novel Scoring System for Predicting Technical Success of Chronic Total Occlusion Percutaneous Coronary Interventions : The PROGRESS-CTO (Prospective Global Registry for the Study of Chronic Total >Occlusion Intervention) Score. JACC Cardiov Interv 2016; 9:1-9, Elsevier.Thompson CA, Jayne JE, Robb JF, Friedman BJ, Kaplan $\mathrm{AV}$, Hettleman BD, et al. Retrograde techniques and the impact of operator volume on percutaneous intervention for coronary chronic total occlusions an early U.S. experience. JACC Cardiovasc Interv. 2009;2:834-42. 


\section{Figure legends}

Figure 1: Chronic total occlusion of the left anterior descending (LAD) artery with collaterals from the right coronary artery (RCA). Retrograde approach. A: before; B: during retrograde approach from $\mathrm{RCA}$; $\mathrm{C}$ : reopening of the $\mathrm{LAD}$, final results.

Figure 2: Decisional algorithm for CTO revascularisation.

Figure 3: Classification of complications of coronary chronic total occlusion interventions. 
Table 1: Utility and futility of CTO angioplasty

\begin{tabular}{|l|c|c|}
\hline & Utility & Futility \\
\hline Clinical & & \\
\hline Uncontrolled symptoms (Angina, dyspnea) & + & - \\
\hline Ischemia in the CTO territory & + & - \\
\hline Viability in the CTO territory & + & - \\
\hline Ventricular arrhythmia & + & - \\
\hline Life expectancy $\geq 1$ year & + & - \\
\hline Technical considerations & & \\
\hline High volume center & + & - \\
\hline Appropriate expertise & + & - \\
\hline Dedicated material availability & + & - \\
\hline Dedicated Cath-lab time & + & - \\
\hline Suitable coronary anatomy & + & - \\
\hline $\begin{array}{l}\text { Risk of failed CTO angioplasty (high J-CTO } \\
\text { score, calcifications, tortuosity) }\end{array}$ & - & + \\
\hline Risk of major complications & - & + \\
\hline
\end{tabular}


Figure 1 Chronic total occlusion of the left anterior descending (LAD) artery with collaterals from the right coronary artery (RCA). Retrograde approach. A: before; $B$ : during retrograde approach from $\mathrm{RCA}$; $\mathrm{C}$ : reopening of the $\mathrm{LAD}$, final results.
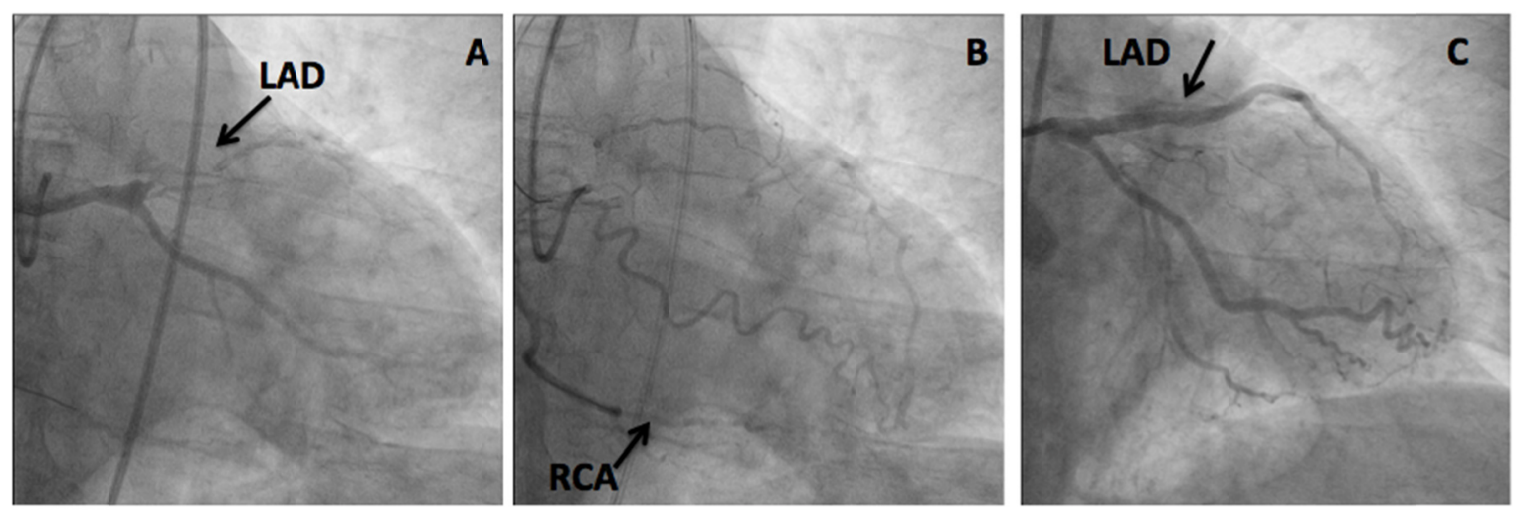
Figure 2: algorithm decision for CTO revascularization.

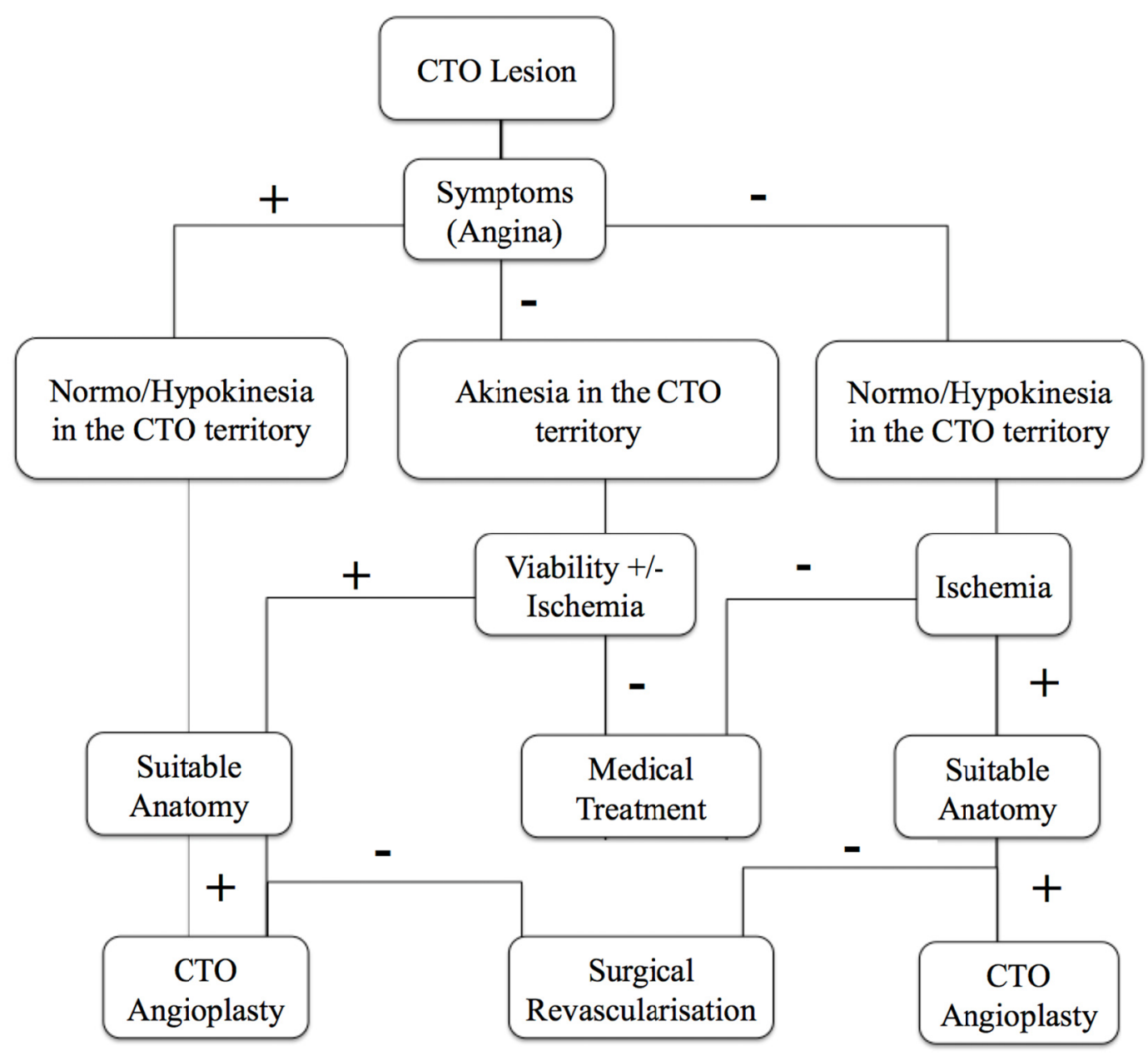


Figure 3: Classification of complications of coronary chronic total occlusion interventions.

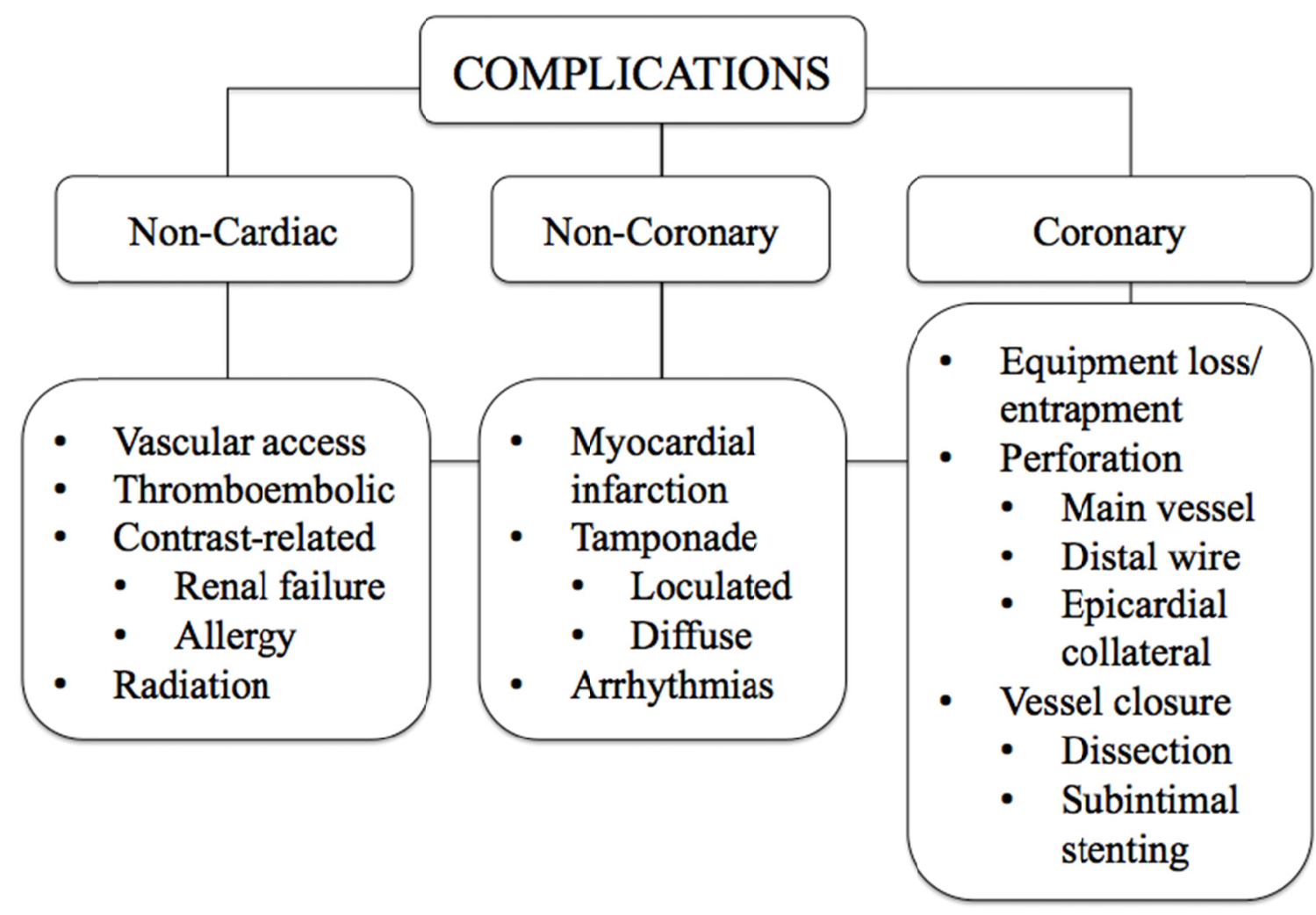

